Article

\title{
Grain Refinement Efficiency in Commercial-Purity Aluminum Influenced by the Addition of Al-4Ti Master Alloys with Varying $\mathrm{TiAl}_{3}$ Particles
}

\author{
Jianhua Zhao ${ }^{1,2, *}$, Jiansheng He ${ }^{1}$, Qi Tang ${ }^{1}$, Tao Wang ${ }^{1}$ and Jing Chen ${ }^{1}$ \\ 1 State Key Laboratory of Mechanical Transmission, College of Materials Science and Engineering, \\ Chongqing University, Chongqing 400044, China; jiansheng.he@cqu.edu.cn (J.H.); \\ 20150901003@cqu.edu.cn (Q.T.); 20113869@cqu.edu.cn (T.W.); 20150902010@cqu.edu.cn (J.C.) \\ 2 National Engineering Research Center for Magnesium Alloys, Chongqing University, \\ Chongqing 400044, China \\ * Correspondence: zjh213@cqu.edu.cn; Tel./Fax: +86-23-6511-2611
}

Academic Editor: Shankar M.L. Sastry

Received: 7 August 2016; Accepted: 21 October 2016; Published: 26 October 2016

\begin{abstract}
A series of Al-4Ti master alloys with various $\mathrm{TiAl}_{3}$ particles were prepared via pouring the pure aluminum added with $\mathrm{K}_{2} \mathrm{TiF}_{6}$ or sponge titanium into three different molds made of graphite, copper, and sand. The microstructure and morphology of $\mathrm{TiAl}_{3}$ particles were characterized and analyzed by scanning electron microscope (SEM) with energy dispersive spectroscopy (EDS). The microstructure of $\mathrm{TiAl}_{3}$ particles in Al-4Ti master alloys and their grain refinement efficiency in commercial-purity aluminum were investigated in this study. Results show that there were three different morphologies of $\mathrm{TiAl}_{3}$ particles in Al-4Ti master alloys: petal-like structures, blocky structures, and flaky structures. The Al-4Ti master alloy with blocky $\mathrm{TiAl}_{3}$ particles had better and more stable grain refinement efficiency than the master alloys with petal-like and flaky $\mathrm{TiAl}_{3}$ particles. The average grain size of the refined commercial-purity aluminum always hereditarily followed the size of the original $\mathrm{TiAl}_{3}$ particles. In addition, the grain refinement efficiency of Al-4Ti master alloys with the same morphology, size, and distribution of $\mathrm{TiAl}_{3}$ particles prepared through different processes was almost identical.
\end{abstract}

Keywords: Al-4Ti; grain refinement; microstructure; morphology

\section{Introduction}

It is well known that metals and alloys usually solidify with coarse columnar grain structures under normal casting condition unless the details and process of solidification are carefully controlled [1,2]. Fine and equiaxed grains could be acquired by adding some master alloys into molten aluminum [3-5]. The cast alloys with equiaxed grain structure have high toughness, high yield strength, excellent formability, good surface finish, and improved ability, achieving a uniform anodized surface, better fatigue life, and good machinability. Thus, there is a quite a need to prepare and develop this type of high performance cast alloy [6,7]. Moreover, a sound grain practice has the following advantages: the avoidance to hot tearing, the allowance for an increase of the casting speed, and the improvement of the casting structure homogeneity by redistribution of the second phases and micro porosity [4,8]. At present, the addition of Al-Ti-B master alloy into the aluminum melt is a common method for grain refinement in industry. Compared with the Al-Ti-B master alloy of high efficiency, the Al-Ti master alloys are considered to be simple and are easily ignored [9-11]. However, the Al-Ti master alloys have been frequently used as a substitute for the Al-Ti-B master alloy in some specific areas, such as aluminum foil, electronic accessories, etc. 
There is no doubt that $\mathrm{TiAl}_{3}$ particles in Al-Ti master alloys act as the centers of heterogeneous nucleation in the mechanism of grain refinement [12]. The morphology, size, and number of the nuclei seem to play important roles in determining the grain refinement efficiency of the master alloys [12-15]. The preparation process and grain refinement performance of Al-Ti and Al-Ti-B master alloys have been investigated in some studies. Those studies mainly focused on the influence of various compositions [16] and processing parameters, such as hold time [17], cooling rate [18], reaction temperature [17,19], and stirring conditions [20] on the grain refinement efficiency. Additionally, most studies paid less attention to the effect of the cooling rate on morphology of $\mathrm{TiAl}_{3}$ particles in $\mathrm{Al}-4 \mathrm{Ti}$ alloys, and the grain refinement performance of petal $\mathrm{TiAl}_{3}$ particles has never been mentioned in the studies. Therefore, the formation process of various $\mathrm{TiAl}_{3}$ particles in Al-4Ti master alloys and their grain refinement performance in commercial-purity aluminum were investigated in this paper.

\section{Experimental}

The Al-4Ti master alloys were acquired by adding $\mathrm{K}_{2} \mathrm{TiF}_{6}$ powders or spongy titanium into commercially-pure aluminum in an electrical resistance furnace at $850{ }^{\circ} \mathrm{C}$. A series of Al-4Ti master alloys with various $\mathrm{TiAl}_{3}$ particles were prepared through different processes as shown in Table 1 . The specimens were taken from the master alloys and glazed by mechanical and electrochemical polishing. For further observation, a solution of $0.5 \%$ hydrofluoric acid (HF) was used to lightly etch all of the specimens. Then the samples were deeply etched in the $10 \% \mathrm{NaOH}$-distilled water solution for $10 \mathrm{~min}$ at $60{ }^{\circ} \mathrm{C}$. The microstructures and three-dimensional morphologies of $\mathrm{TiAl}_{3}$ particles in Al-4Ti alloys were characterized by using TESCANVEGA II scanning electron microscope (SEM) (TESCAN, Bruno, Czech Republic) with light element energy dispersive spectroscopy (EDS) $\mathrm{X}$-ray detectors.

Table 1. Process details of the Al-4Ti master alloys.

\begin{tabular}{cccc}
\hline Cast Material & Addition & Mold Materials & Alloy Designation \\
\hline & & Graphite & I \\
& $\mathrm{K}_{2} \mathrm{TiF}_{6}$ & Copper & II \\
Pure aluminum & & Sand & III \\
& & Graphite & IV \\
& Sponge titanium & Copper & V \\
& & Sand & VI \\
\hline
\end{tabular}

To evaluate the grain refinement performance, the master alloys I, II, III, IV, V, and VI, which occupied about $0.2 \mathrm{wt}$ \% of the whole melts, were independently added into the commercial-purity aluminum ingots at $720{ }^{\circ} \mathrm{C}$, which was proved to be the temperature with the highest recovery of titanium [17]. The melts were kept in the resistance furnace for 5, 10, 30, 60, and $120 \mathrm{~min}$, respectively, and then poured into a ring-like mold made of steel. The shape and other details of the mold were shown in Figure 1. The samples were directly etched by the mixed acid reagent $\left(87.5 \% \mathrm{HCl}+10 \% \mathrm{HNO}_{3}+2.5 \% \mathrm{HF}\right)$. Finally, the grain size of the refined samples were observed and analyzed by a Carl Zeiss Microscopy (GmbH 37081, Göttingen, Germany). 

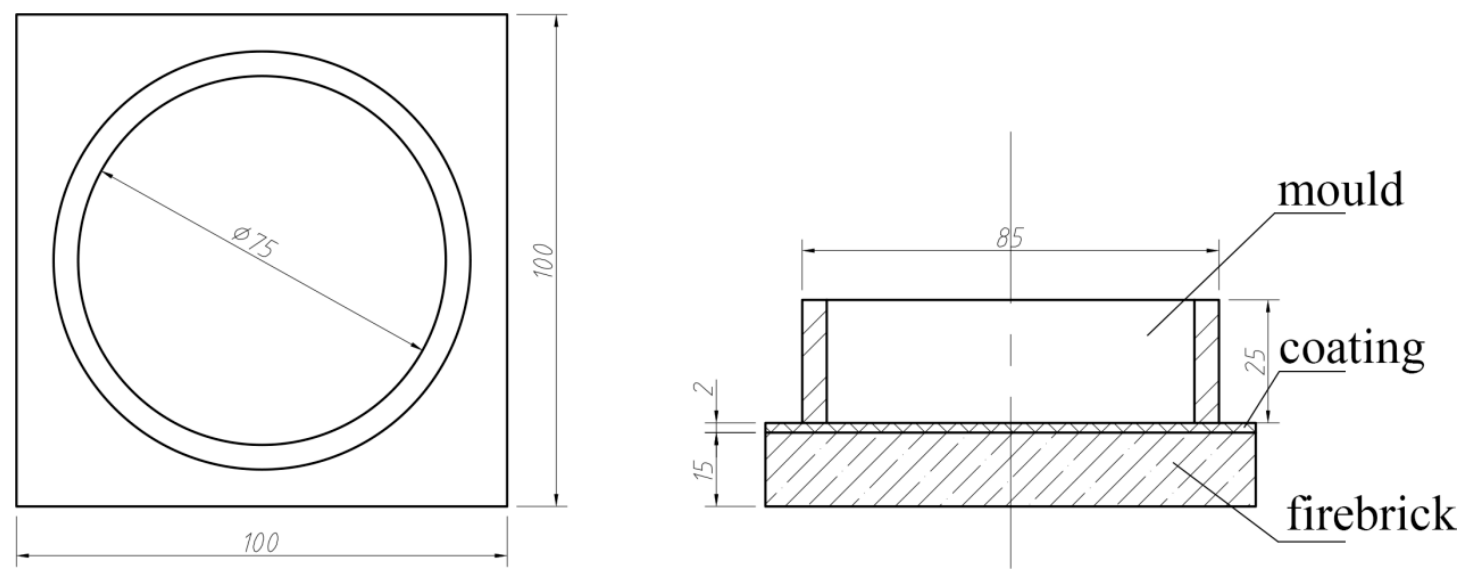

Figure 1. Schematic illustration of the mold for grain refinement evaluation.

\section{Results and Discussion}

\subsection{Microstructures and Morphologies}

The microstructures of Al-4Ti master alloys (I, II, and III) and the three-dimensional morphologies of $\mathrm{TiAl}_{3}$ particles are shown in Figures 2-4, respectively. It can be found that the $\mathrm{TiAl}_{3}$ intermetallic particles had three different morphologies: petal-like structures, blocky structures, and flaky structures, the formations of which have a very tight connection to the additions and mold materials. This is in agreement with the reports from Arnberg et al. [21] and Liu et al. [22]. The petal-like $\mathrm{TiAl}_{3}$ particles tend to form at low melting temperatures and high cooling rates. The blocky $\mathrm{TiAl}_{3}$ particles are more likely to generate at low melt temperatures and medium cooling rates, while the flaky $\mathrm{TiAl}_{3}$ particles are inclined to grow at high melt temperatures and low cooling rates.

Figure 2 shows the microstructure of Al-4Ti master alloy I and the three-dimensional morphologies of petal-like $\mathrm{TiAl}_{3}$ particles. According to Figure $2 \mathrm{a}-\mathrm{c}$, it can be observed that petal-like $\mathrm{TiAl}_{3}$ particles distribute uniformly on the aluminum substrate, which can also be found in the study of Arnberg et al. [23]. Figure 2d-f exhibit the three-dimensional morphologies of petal-like $\mathrm{TiAl}_{3}$ particles in Al-4Ti master alloy I. Based on Figure 2d, it could be deduced that the free-distributed $\mathrm{TiAl}_{3}$ particles were treated as nucleation centers, from which all of the petals started to grow. During the whole process, Ti atoms had to be diffused and transported a long distance to fill the deficiency of titanium for marginal growth and, thus, the growth rate of petals would decrease as the cooling time increased. It was not until the adjacent petals contacted with each other that the petal-like $\mathrm{TiAl}_{3}$ particles would stop growing. Due to the change of growth rate, the $\mathrm{TiAl}_{3}$ particles in the $\mathrm{Al}-4 \mathrm{Ti}$ master alloy I were in the shape of petals with cusps. In Figure 2f, it could be found that the growth of $\mathrm{TiAl}_{3}$ particles might conform to a twinning mechanism. With the decrease of the melt temperature, the undercooling between (001) and the melt interface increased to a new level, which was not enough to form a new phase. On the basis of the twinning growth mechanism, a new plane formed and grew at the intersection of the new and old c-axes, which were mutually perpendicular [18]. Until the titanium at the margin was run out, the petals would stop growing. After that, the growth of $\mathrm{TiAl}_{3}$ would follow the twinning mechanism. As a result, the petal-like $\mathrm{TiAl}_{3}$ particles were formed in $\mathrm{Al}-4 \mathrm{Ti}$ master alloy I. 


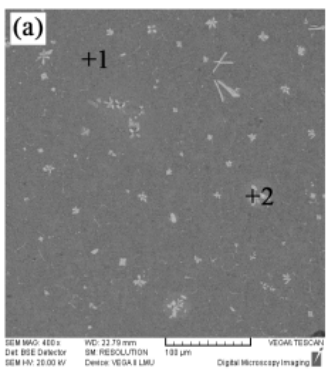

(b)

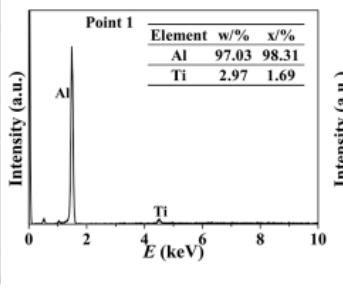

(c)

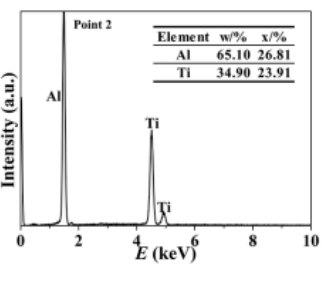

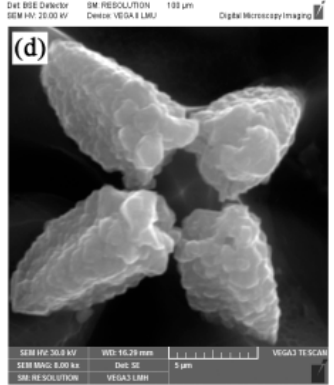
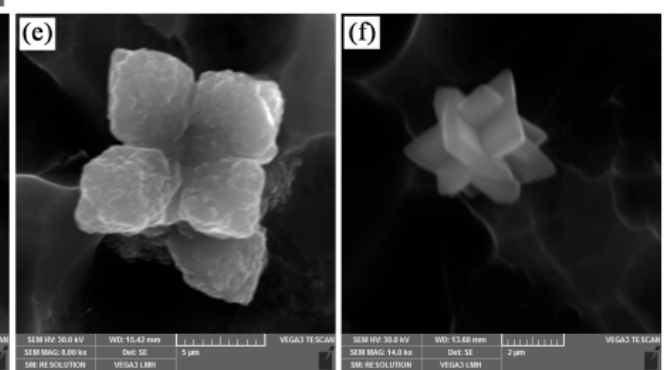

Figure 2. (a) SEM micrograph of the Al-4Ti master alloy I; (b,c) EDS spectra of points 1 and 2 marked in (a), respectively; and (d-f) three-dimensional morphologies of the petal-like TiAl3 particles.

Figure 3 displays the microstructure of Al-4Ti master alloy II and the three-dimensional morphologies of blocky $\mathrm{TiAl}_{3}$ particles. In accordance with the EDS spectra in Figure $3 \mathrm{~b}, \mathrm{c}$, it reveals that these white blocks were $\mathrm{TiAl}_{3}$ particles and the dark substrate was aluminum. As shown in Figure 3d-f, the $\mathrm{TiAl}_{3}$ particles present a tetrahedral or hexahedral structure, which also existed in Al-Ti and Al-Ti-C master alloys after rapid solidification [18,24,25]. This confirms the results of Wang et al. [26] that $\mathrm{TiAl}_{3}$ particles present a tetragonal structure. When titanium content was super-saturated in the melt, the blocky $\mathrm{TiAl}_{3}$ particles would form. In this case, the nuclear driving force of $\mathrm{TiAl}_{3}$ was enough to support the nucleation on the densest atomic plane of the original crystal, and the growth rate in the direction of [001] could not be ignored [27]. The influence of Ti atom diffusion was so little that the tendency of preferred growth was not also conspicuous. Therefore, the growth rates of all crystal planes were equalized and the blocky $\mathrm{TiAl}_{3}$ particles could be formed in the Al-4Ti master alloy II.
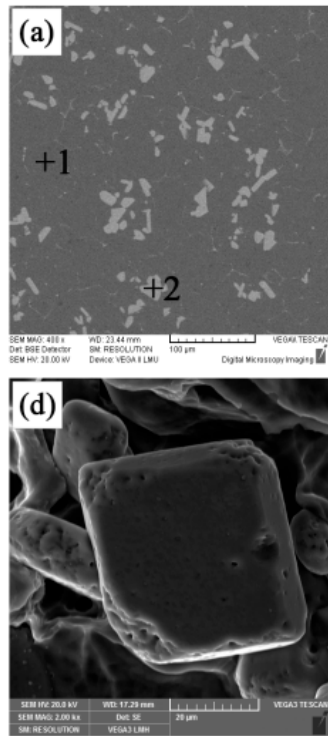

(b)

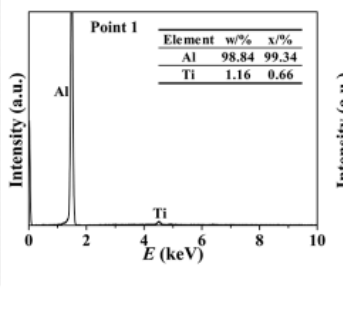

(c)
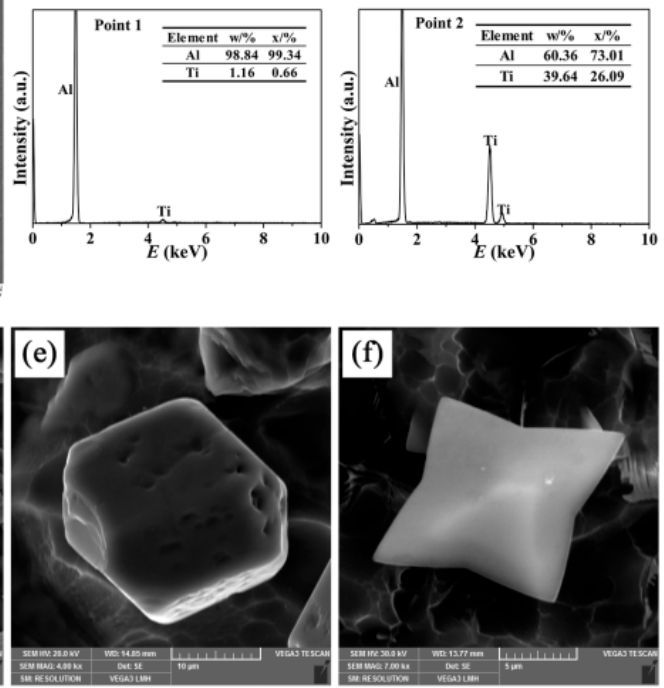

Figure 3. (a) SEM micrograph of the Al-4Ti master alloy II; $(\mathbf{b}, \mathbf{c})$ EDS spectra of points 1 and 2 marked in (a) respectively; and (d-f) three-dimensional morphologies of the blocky $\mathrm{TiAl}_{3}$ particles. 
Figure 4 exhibits the microstructure of Al-4Ti master alloy III and the three-dimensional morphologies of flaky $\mathrm{TiAl}_{3}$ particles. The $\mathrm{TiAl}_{3}$ particles were in needle-like structures in two dimensions and formed flaky structures in three dimensions. The existence of $\mathrm{TiAl}_{3}$ particles could be confirmed by EDS analysis, as shown in Figure 4c. It could be observed from Figure 4d,e that there were some embossments on the surfaces of flaking. In addition, Figure 4e shows that the aspect ratio of the flaky $\mathrm{TiAl}_{3}$ particles is larger than the blocky ones, which indicates that the growth of these flaky particles was influenced by strain energy. Lee et al. proposed an explanation that the flaky particles are formed in the solid phase by precipitation from a supersaturated solid solution of titanium in an aluminum melt [28]. The flaky $\mathrm{TiAl}_{3}$ intermetallic compounds were two-dimensional dendrite crystals, which meant that the growth rates in the [100], [010], and [110] directions were identical. However, the (001) crystal plane had the maximum atomic density, and the growth rate in the [001] direction was the lowest [26]. Finally, the flaky $\mathrm{TiAl}_{3}$ particles were formed in Al-4Ti master alloy III, which is also consistent with the forecast of Flemings [2].
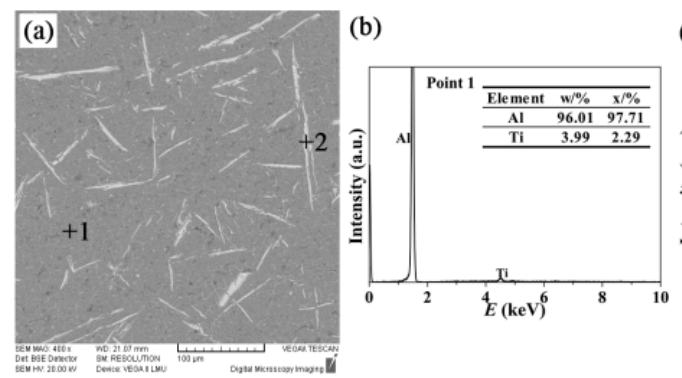

(c)
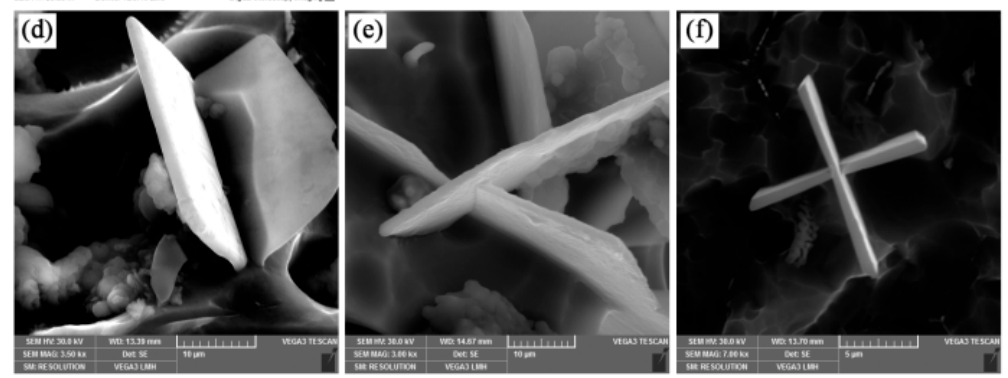

Figure 4. (a) SEM micrograph of the Al-4Ti master alloy III; (b,c) EDS spectra of points 1 and 2 marked in (a) respectively; and $(\mathbf{d}-\mathbf{f})$ three-dimensional morphologies of the flaky $\mathrm{TiAl}_{3}$ particles.

The microstructural parameters of different Al-4Ti master alloys prepared in the experiment are shown in Table 2. When $\mathrm{K}_{2} \mathrm{TiF}_{6}$ was added into the commercial-purity aluminum, the morphology of $\mathrm{TiAl}_{3}$ particles experienced a transformation from petal-like structures to blocky structures, and then to flaky structures as the cooling rate decreased. At high cooling rates, the solidification time was too short to support growth and, thus, the majority of petal-like $\mathrm{TiAl}_{3}$ particles were tiny. By comparison, when the commercial-purity aluminum added with the sponge titanium was cast into all three kinds of molds, there was no petal-like $\mathrm{TiAl}_{3}$ particle in the Al-4Ti master alloys. In addition, the $\mathrm{TiAl}_{3}$ particles in Al-4Ti master alloys IV and V displayed a blocky structure but had different sizes. This means that not only the morphologies of $\mathrm{TiAl}_{3}$ particles in Al-4Ti master alloys, but also the grain sizes of the blocky particles, were deeply related to the cooling rate. In general, the petal-like $\mathrm{TiAl}_{3} \mathrm{particles}$ were only formed when the aluminum melt augmented with $\mathrm{K}_{2} \mathrm{TiF}_{6}$ was casted into the graphite mold. On one hand, the addition of $\mathrm{K}_{2} \mathrm{TiF}_{6}$ could distribute uniformly in the aluminum melt, while the addition of sponge titanium would sink and aggregate to produce some titanium super-saturation areas, which might not be beneficial to the formation of petal-like $\mathrm{TiAl}_{3}$ particles. On the other hand, the addition of $\mathrm{K}_{2} \mathrm{TiF}_{6}$ may cause the alteration of the preferential growth orientation of $\mathrm{TiAl}_{3}$ crystals. Furthermore, the grain size of different $\mathrm{TiAl}_{3}$ particles in Al-4Ti master alloys increased gradually with the decrease of the cooling rate within the same additions. 
Table 2. Microstructural parameters of $\mathrm{TiAl}_{3}$ particles in $\mathrm{Al}-4 \mathrm{Ti}$ master alloys.

\begin{tabular}{cccc}
\hline Alloy & Morphology & Average Length, $\boldsymbol{\mu m}$ & Quantity, $\mathbf{c m}^{\mathbf{2}}$ \\
\hline I & Petal-like & 11 & 24,340 \\
II & Blocky & 16 & 20,411 \\
III & Needle-like & 90 & 7462 \\
IV & Blocky & 13 & 23,750 \\
V & Blocky & 22 & 17,900 \\
VI & Needle-like & 106 & 6358 \\
\hline
\end{tabular}

\subsection{Refinement Performance of Al-4Ti Master Alloys}

Additional experiments were employed to evaluate the effects of hold time on the refinement efficiency of Al-4Ti master alloys with different types of $\mathrm{TiAl}_{3}$ particles in commercial-purity aluminum. The macrostructures of commercial-purity aluminum refined by Al-4Ti master alloys I, II, and III, respectively, were shown in Figures 5-7. There existed many differences of grain refinement efficiency among the various types of Al-4Ti master alloys. After comprehensive analysis of all of the hold times, the grain refinement efficiency of the Al-4Ti master alloy I with petal-like $\mathrm{TiAl}_{3}$ particles decreased gradually, and then increased sharply, as shown in Figure 5. The grain size of commercial-purity aluminum reached the maximum when the hold time was $60 \mathrm{~min}$. Additionally, both the grain size of commercial-purity aluminum refined for $5 \mathrm{~min}$ and $120 \mathrm{~min}$ was about $65 \mu \mathrm{m}$. The results in this study reach agreement with the discoveries of $\mathrm{Li}$ et al. [13] regarding the grain refinement performance of the Al-4Ti master alloy with both flaky and blocky $\mathrm{TiAl}_{3}$ particles. When Al-4Ti master alloy I was added into commercial-purity aluminum, the free petal-like $\mathrm{TiAl}_{3}$ particles worked as the nuclei, leading to an improvement of grain refinement efficiency. Some $\mathrm{TiAl}_{3}$ particles formed according to the repeated twinning mechanism might break into small flakes to provide more nuclei, which could also promote the grain refinement efficiency. However, some petal-like $\mathrm{TiAl}_{3}$ particles (Figure 2f) dissolved gradually, and the number of heterogeneous nuclei would reduce, which caused the further growth in grain size. Moreover, some petal-like $\mathrm{TiAl}_{3}$ particles (Figure $2 \mathrm{~d}$,e) would break into small blocks which could prevent the small flakes mentioned before from dissolving. Therefore, it could be deduced that the various types of $\mathrm{TiAl}_{3}$ particles could transform into each other, and the blocky $\mathrm{TiAl}_{3}$ particles could effectively prevent the small flakes, decomposed by the petal-like particles, from dissolving.
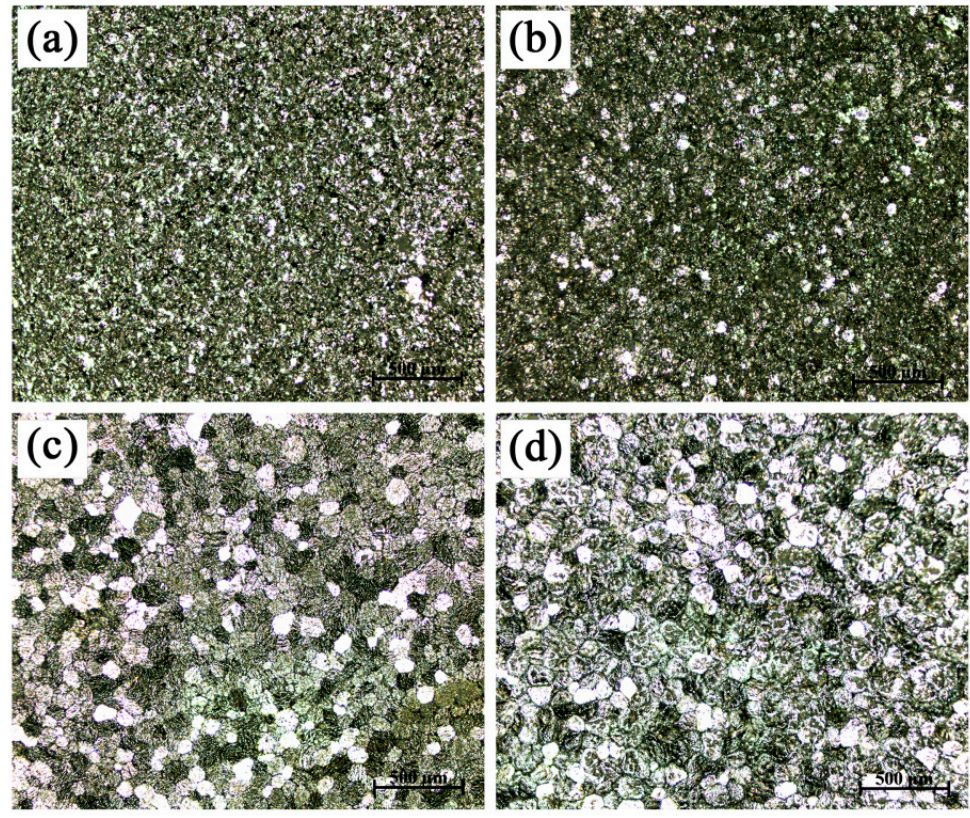

Figure 5. Cont. 


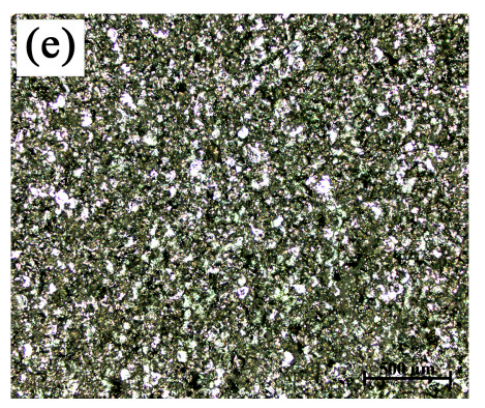

Figure 5. Macrostructures of commercial-purity aluminum sample refined by Al-4Ti master alloy I (0.2 wt. \%) after different hold times: (a) $5 \mathrm{~min}$; (b) $10 \mathrm{~min}$; (c) $30 \mathrm{~min}$; (d) $60 \mathrm{~min}$; and (e) $120 \mathrm{~min}$.

As can be seen from Figure 6, the grain refinement efficiency of the Al-4Ti master alloy II with blocky $\mathrm{TiAl}_{3}$ particles was the best and did not fade away with the change of the hold time. The grain refinement performance of the Al-4Ti master alloy with blocky $\mathrm{TiAl}_{3}$ particles was better than that of the master alloy I with petal-like $\mathrm{TiAl}_{3}$ particles. As for the master alloy III with flaky $\mathrm{TiAl}_{3}$ particles, the conversion from coarse columnar grains to fine equiaxed grains was completed within 2 min (Figure 7). The grain refinement performance of the master alloy III with flaky $\mathrm{TiAl}_{3}$ particles would worsen as the hold time increased. The grain size of commercial-purity aluminum reached the maximum when the hold time was $120 \mathrm{~min}$. This was because the dissolution of all of the flaky $\mathrm{TiAl}_{3}$ particles, with the increase of hold time, provided fewer nuclei.
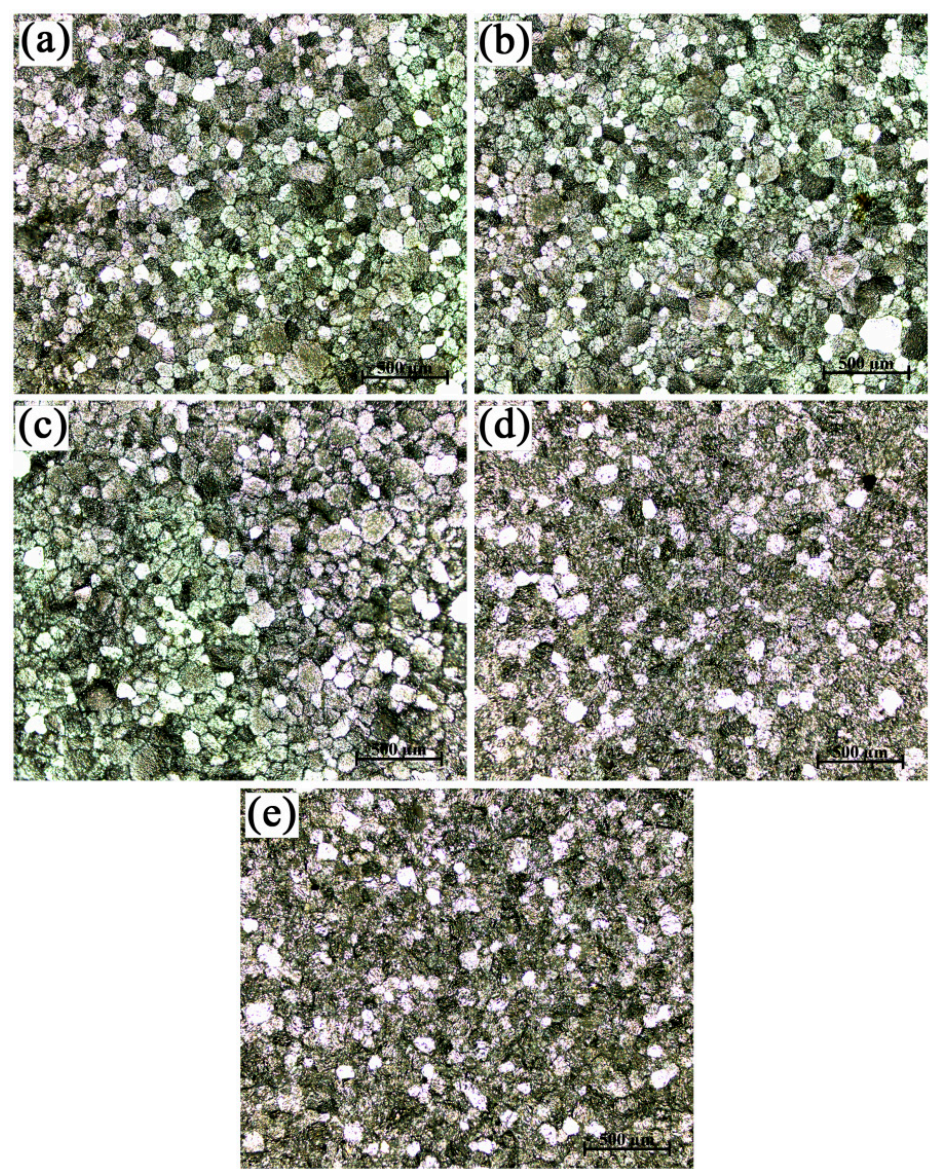

Figure 6. Macrostructures of commercial-purity aluminum sample refined by Al-4Ti master alloy II (0.2 wt. \%) after different hold times: (a) $5 \mathrm{~min}$; (b) $10 \mathrm{~min}$; (c) $30 \mathrm{~min}$; (d) $60 \mathrm{~min}$; and (e) $120 \mathrm{~min}$. 


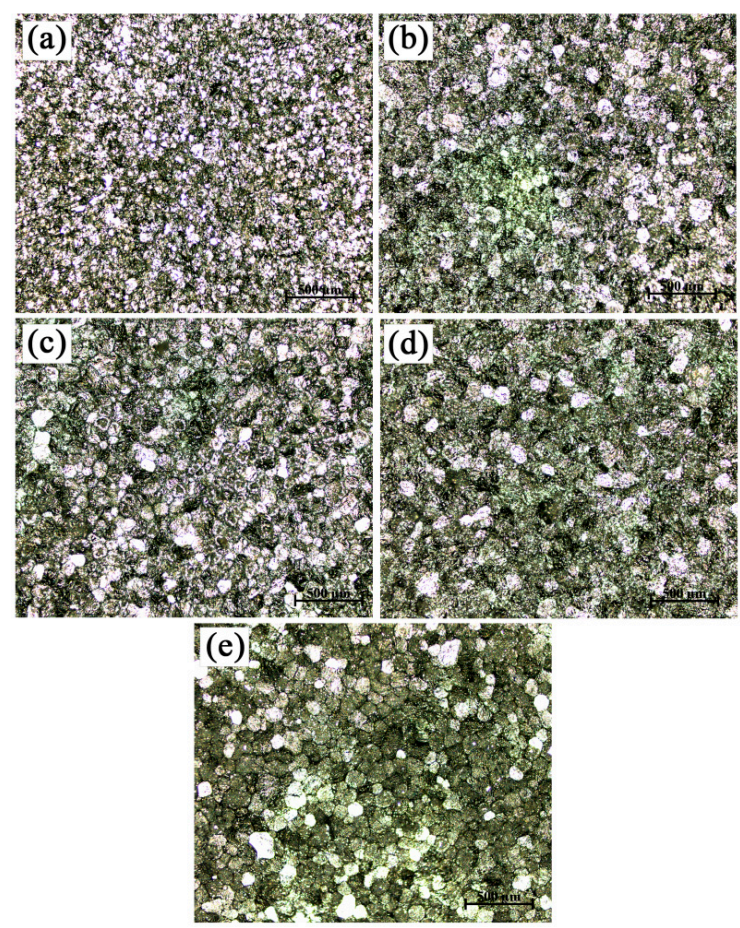

Figure 7. Macrostructures of commercial-purity aluminum sample refined by Al-4Ti master alloy III (0.2 wt. \%) after different hold times: (a) $5 \mathrm{~min}$; (b) $10 \mathrm{~min}$; (c) $30 \mathrm{~min}$; (d) $60 \mathrm{~min}$; (e) $120 \mathrm{~min}$.

Figure 8 shows the relationships between average grain size and hold time of the Al-4Ti master alloys I, II, III, IV, V, and VI. It was found that the grain refinement efficiency of the master alloy I with petal-like $\mathrm{TiAl}_{3}$ particles decreased and then strengthened. For the master alloys III and VI with flaky $\mathrm{TiAl}_{3}$ particles, the grain size of commercial-purity aluminum went up with the increase of the hold time. The three curves of the master alloys II, IV, and V with blocky $\mathrm{TiAl}_{3}$ particles remained level and stable. Therefore, the grain refinement efficiency of the master alloys with blocky $\mathrm{TiAl}_{3}$ particles was better than the master alloys with petal-like and flaky $\mathrm{TiAl}_{3}$ particles under the same condition of addition. The grains in commercial-purity aluminum after grain refinement of Al-4Ti master alloys also showed a hereditary effect of the original grain size. The average grain size of the refined commercial-purity aluminum always hereditarily followed the size of the original $\mathrm{TiAl}_{3}$ particles. In addition, it could be also deduced that no matter what the preparation process was, only the grain refinement efficiency of Al-4Ti master alloys with the same morphology, size, and distribution of $\mathrm{TiAl}_{3}$ particles was almost the same.

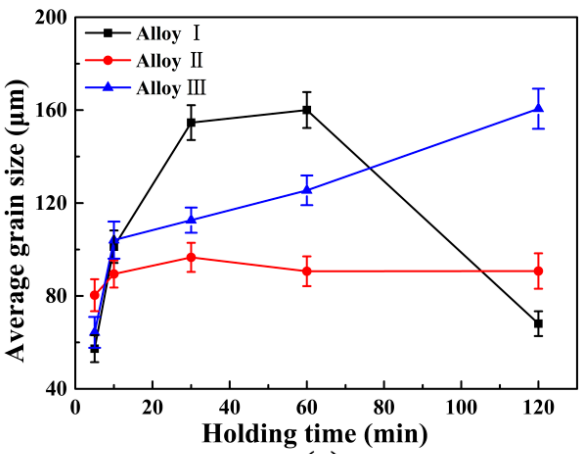

(a)

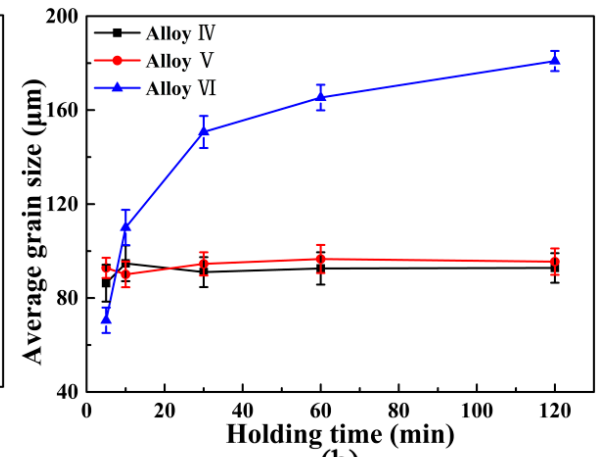

(b)

Figure 8. Relationships between average grain size and hold time: (a) the Al-4Ti master alloys I, II, and III; and (b) the Al-4Ti master alloys IV, V, and VI. 


\section{Conclusions}

In this work, the formation process of various $\mathrm{TiAl}_{3}$ particles in $\mathrm{Al}-4 \mathrm{Ti}$ master alloys and their grain refinement performance in commercial-purity aluminum were studied. The major findings are as follows:

(i) There were three different types of $\mathrm{TiAl}_{3}$ particles in Al-4Ti master alloys: petal-like structures, blocky structures, and flaky structures. The petal-like $\mathrm{TiAl}_{3}$ particles were only formed according to the growth mechanism of repeated twins when the aluminum melt augmented with $\mathrm{K}_{2} \mathrm{TiF}_{6}$ was casted into the graphite mold. Whether the $\mathrm{K}_{2} \mathrm{TiF}_{6}$ or sponge titanium was added into the aluminum melt which was cast into the sand mold, the flaky $\mathrm{TiAl}_{3}$ particles were generated. In addition, the blocky $\mathrm{TiAl}_{3}$ particles were found after the remaining three different processes.

(ii) The grains in commercial-purity aluminum after grain refinement of Al-4Ti master alloys showed a hereditary effect on grain size. The larger the average grain sizes of the original $\mathrm{TiAl}_{3}$ particles were, the larger that of the refined commercial-purity aluminum was.

(iii) With the increase in the hold time, the grain size of the commercial-purity aluminum refined by the Al-4Ti master alloy with petal-like $\mathrm{TiAl}_{3}$ particles increased, at first, and then decreased rapidly. The grain refinement efficiency of the Al-4Ti master alloy with blocky $\mathrm{TiAl}_{3}$ particles was the best and did not fade away with the change of the hold time. The Al-4Ti master alloy with flaky $\mathrm{TiAl}_{3}$ particles could instantly achieve a fine grain refinement under a hold time of five minutes; however, the fine refinement efficiency went down as the hold time increased.

(iv) The grain refinement efficiency of Al-4Ti master alloys with the same morphology, size, and distribution of $\mathrm{TiAl}_{3}$ particles prepared through different processes was almost identical.

Acknowledgments: This research was financially supported by the Natural Science Foundation of Chongqing City in China (Grant No. cstc2015yykfC50001). The authors would like to thank the National Engineering Research Center for Magnesium Alloys and School of Materials Science and Engineering of Chongqing University for technological support.

Author Contributions: Jiansheng He interpreted the results and wrote the manuscript. Jing Chen conceived and designed the experiments. Qi Tang and Tao Wang performed experiments under the guidance of Jianhua Zhao. All of the authors contributed to the discussions.

Conflicts of Interest: The authors declare no conflict of interest.

\section{References}

1. Murty, B.S.; Kori, S.A.; Chakraborty, M. Grain refinement of aluminium and its alloys by heterogeneous nucleation and alloying. Int. Mater. Rev. 2002, 47, 3-29. [CrossRef]

2. Flemings, M.C. Solidification processing. Metall. Trans. 1974, 5, 2121-2134. [CrossRef]

3. Hassanbeygi, V.; Shafyei, A. Investigation on microstructure and grain refining performance of a new type of Al-3Ti-1C master alloy. OJMetal 2014, 4, 49-55. [CrossRef]

4. Birol, Y. Effect of the salt addition practice on the grain refining efficiency of Al-Ti-B master alloys. J. Alloys Compd. 2006, 420, 207-212. [CrossRef]

5. Birol, Y. An improved practice to manufacture Al-Ti-B master alloys by reacting halide salts with molten aluminium. J. Alloys Compd. 2006, 420, 71-76. [CrossRef]

6. Auradi, V.; Kori, S.A. Effect of processing temperature on the microstructure of Al-7Ti master alloy and on refinement of $\alpha$-Al dendrites in Al-7Si alloys. Adv. Mater. Lett. 2015, 6, 252-259. [CrossRef]

7. Kashyap, K.T.; Chandrashekar, T. Effects and mechanisms of grain refinement in aluminium alloys. Bull. Mater. Sci. 2001, 24, 345-353. [CrossRef]

8. Jones, G.P.; Pearson, J. Factors affecting the grain-refinement of aluminum using titanium and boron additives. Metall. Trans. B 1976, 7, 223-234. [CrossRef]

9. Birol, Y. AlB3 master alloy to grain refine AlSi10Mg and AlSi12Cu aluminium foundry alloys. J. Alloys Compd. 2012, 513, 150-153. [CrossRef]

10. Savas, O.; Kayikci, R.A. Taguchi optimisation for production of Al-B master alloys using boron oxide. J. Alloys Compd. 2013, 580, 232-238. [CrossRef] 
11. Easton, M.A.; StJohn, D.H. A model of grain refinement incorporating alloy constitution and potency of heterogeneous nucleant particles. Acta Mater. 2001, 49, 1867-1878. [CrossRef]

12. Guzowski, M.M.; Sigworth, G.K.; Sentner, D.A. The role of boron in the grain-refinement of aluminum with titanium. Metall. Trans. A Phys. Metall. Mater. Sci. 1987, 18, 603-619. [CrossRef]

13. Li, P.; Kandalova, E.G.; Nikitin, V.I. Grain refining performance of Al-Ti master alloys with different microstructures. Mater. Lett. 2005, 59, 723-727. [CrossRef]

14. Fan, Z.; Wang, Y.; Zhang, Y.; Qin, T.; Zhou, X.R.; Thompson, G.E.; Pennycook, T.; Hashimoto, T. Grain refining mechanism in the Al/Al-Ti-B system. Acta Mater. 2015, 84, 292-304. [CrossRef]

15. Li, H.; Sritharan, T.; Lam, Y.M.; Leng, N.Y. Effects of processing parameters on the performance of $\mathrm{Al}$ grain refinement master alloys Al Ti and Al B in small ingots. J. Mater. Process. Technol. 1997, 66, 253-257. [CrossRef]

16. Li, P.T.; Ma, X.G.; Li, Y.G.; Nie, J.F.; Liu, X.F. Effects of trace $\mathrm{C}$ addition on the microstructure and refining efficiency of Al-Ti-B master alloy. J. Alloys Compd. 2010, 503, 286-290. [CrossRef]

17. Birol, Y. The effect of holding conditions in the conventional halide salt process on the performance of Al-Ti-B grain refiner alloys. J. Alloys Compd. 2007, 427, 142-147. [CrossRef]

18. Majumdar, A.; Muddle, B.C. Microstructure in rapidly solidified Al-Ti alloys. Mater. Sci. Eng. A Struct. Mater. Prop. Microstruct. Process. 1993, 169, 135-147. [CrossRef]

19. Birol, Y. Al-Ti-B grain refiners via powder metallurgy processing of $\mathrm{Al} / \mathrm{K} 2 \mathrm{TiF} 6 / \mathrm{KBF} 4$ powder blends. J. Alloys Compd. 2009, 480, 311-314. [CrossRef]

20. Zhao, Z.; Guan, R.; Guan, X.; Zhang, J.; Sun, X.; Liu, H. Effects of electromagnetic stirring, shearing, and extrusion on $\mathrm{TiB}_{2}$ and $\mathrm{TiAl}_{3}$ Particles in $\mathrm{Al}-5 \mathrm{Ti}-1 \mathrm{~B}($ wt. \%) Alloy. Mater. Manuf. Process. 2015, 30, 1223-1228. [CrossRef]

21. Arnberg, L.; Backerud, L.; Klang, H. Grain refinement of aluminum by addition of master alloys of the Al-Ti-B type. In The Czech Aluminum Symposium, Fourth, Extended Abstracts; Mid-County Press: London, UK, 1980; pp. 17-26.

22. Liu, X.F.; Bian, X.F.; Yang, Y. The formation law of $\mathrm{TiAl}_{3}$ morphologies in $\mathrm{AlTi}_{5} \mathrm{~B}$ master alloy. Spec. Cast. Nonferrous Alloys 1997, 5, 4-6.

23. Arnberg, L.; Bäckerud, L.; Klang, H. Production and properties of master alloys of Al-Ti-B type and their ability to grain refine aluminium. Met. Technol. 1982, 9, 1-6. [CrossRef]

24. Ding, W.W.; Zhang, X.Y.; Zhao, W.J.; Xia, T.D.; Zhang, H.X. Microstructure evolution and grain refining performance of new green kind of Al-5Ti-C master alloy. Int. J. Cast Met. Res. 2015, 28, 89-96. [CrossRef]

25. Wang, T.; Gao, T.; Nie, J.; Li, P.; Liu, X. Influence of carbon source on the microstructure of Al-Ti-C master alloy and its grain refining efficiency. Mater. Charact. 2013, 83, 13-20. [CrossRef]

26. Wang, Z.Q.; Liu, X.F.; Liu, Y.H.; Zhang, J.Y.; Yu, L.N.; Bian, X.F. Structural heredity of TiC and its influences on refinement behaviors of AlTiC master alloy. Trans. Nonferrous Met. Soc. China 2003, 13, 790-793.

27. Arnberg, L.; Backerud, L.; Klang, H. Intermetallic particles in Al-Ti-B-type master alloys for grain-refinement of aluminum. Met. Technol. 1982, 9, 7-13. [CrossRef]

28. Lee, M.S.; Terry, B.S. Effects of processing parameters on aluminide morphology in aluminium grain refining master alloys. Mater. Sci. Technol. 1991, 7, 608-612. [CrossRef]

(C) 2016 by the authors; licensee MDPI, Basel, Switzerland. This article is an open access article distributed under the terms and conditions of the Creative Commons Attribution (CC-BY) license (http://creativecommons.org/licenses/by/4.0/). 